\title{
Meta-analysis of laparoscopic anterior resection with natural orifice specimen extraction (NOSE-LAR) versus abdominal incision specimen extraction (AISE-LAR) for sigmoid or rectal tumors
}

\author{
Jun He${ }^{1}$, Hai-Bo Yao ${ }^{2}$, Chang-Jian Wang ${ }^{1}$, Qin-Yan Yang ${ }^{1}$, Jian-Ming Qiu' ${ }^{1}$ Jin-Ming Chen ${ }^{1}$, Zhong Shen ${ }^{1}$ and
} Guan-Gen Yang ${ }^{1 *}$ (D)

\begin{abstract}
Background: Natural orifice specimen extraction surgery is a novel technique of minimally invasive surgery. The purpose of this study was to compare the safety of laparoscopic anterior resection with natural orifice specimen extraction (NOSE-LAR) and abdominal incision specimen extraction (AISE-LAR) for sigmoid or rectum tumors.

Methods: MEDLINE (PubMed), Embase, CENTRAL (Cochrane Central Register of Controlled Trials), Scopus, and ClinicalTrials databases were systematically searched for related articles up to August 2019. The primary outcomes included postoperative complications (overall postoperative complication, incision-related complication, anastomotic fistula, and severe complication) and pathologic results (lymph nodes harvested, proximal resection margin, and distal resection edge). The statistical analysis was performed on STATA 12.0 software.
\end{abstract}

Results: Ten studies comprising 1787 patients were used for meta-analysis. Compared with AISE-LAR, NOSE-LAR had more advantages in terms of overall postoperative complication (odds ratio $(\mathrm{OR})=0.65(95 \% \mathrm{Cl}, 0.46$ to $0.90 ; P=0.01)$ ), incision-related complication ( $\mathrm{OR}=0.13(95 \% \mathrm{Cl}, 0.05$ to $0.35 ; P<0.01)$ ), distal resection edge (weighted mean difference $(\mathrm{WMD})=0.17 \mathrm{~cm}(95 \% \mathrm{Cl}, 0.02$ to $0.33 \mathrm{~cm} ; P=0.02))$, recovery of gastrointestinal function $(\mathrm{WMD}=-0.38$ day $(95 \% \mathrm{Cl},-0.70$ to -0.06 day; $P=0.02))$, pain scores in postoperative day $1(\mathrm{WMD}=-1.64(95 \% \mathrm{Cl},-2.31$ to $0.98 ; P<0.01))$, additional analgesics usage $(\mathrm{OR}=0.21(95 \% \mathrm{Cl}, 0.11$ to $0.40 ; P<0.01))$ and hospital stay $(\mathrm{WMD}=-0.71$ day $(95 \% \mathrm{Cl},-1.10$ to -0.32 day; $P<0.01)$ ), while the operation time of NOSE-LAR was prolonged (WMD $=7.4 \mathrm{~min}$ (95\% Cl, 0.17 to $14.64 \mathrm{~min} ; P=0.04)$ ). The anastomotic fistula, severe complication, lymph nodes harvested, proximal resection margin, intraoperative blood loss, and long-term outcomes in NOSE-LAR were comparable with AISE-LAR.

Conclusions: The safety of NOSE-LAR was demonstrated, and it could be an alternative to conventional surgery in laparoscopic anterior resection for sigmoid and rectal tumors. However, further randomized and multi-center trials are required.

Keywords: Natural orifice specimen extraction, NOSE, Laparoscopic anterior resection, Rectal tumor, Sigmoid tumor, Metaanalysis

\footnotetext{
* Correspondence: guangenyang@163.com

'Department of Colorectal Surgery, Hangzhou Third Hospital, Hangzhou 310009 Zhejiang, People's Republic of China

Full list of author information is available at the end of the article
}

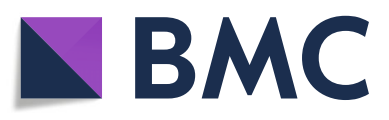

( ) The Author(s). 2020 Open Access This article is licensed under a Creative Commons Attribution 4.0 International License, which permits use, sharing, adaptation, distribution and reproduction in any medium or format, as long as you give appropriate credit to the original author(s) and the source, provide a link to the Creative Commons licence, and indicate if changes were made. The images or other third party material in this article are included in the article's Creative Commons licence, unless indicated otherwise in a credit line to the material. If material is not included in the article's Creative Commons licence and your intended use is not permitted by statutory regulation or exceeds the permitted use, you will need to obtain permission directly from the copyright holder. To view a copy of this licence, visit http://creativecommons.org/licenses/by/4.0/. The Creative Commons Public Domain Dedication waiver (http://creativecommons.org/publicdomain/zero/1.0/) applies to the data made available in this article, unless otherwise stated in a credit line to the data. 


\section{Introduction}

Over the past three decades, laparoscopic surgery has evolved incessantly, especially in the field of colorectal surgery. It has been widely accepted by surgeons and patients in light of the better peri-operative outcomes and analogical long-term effectiveness compared with open surgery for colorectal cancers [1-3].

For conventional laparoscopic colorectal operation, a small laparotomy in the abdomen is required for specimen harvested and colorectal anastomosis. Because of the mini-incision, it causes many undesirable outcomes such as incision pain, wound infection, scar, and even incision hernia, and the advantages of laparoscopic surgery are reduced [4-6]. To minimize those drawbacks, a novel surgical variant known as natural orifice specimen extraction (NOSE) surgery, with the features of natural orifice specimen extraction and total intraperitoneal anastomosis, has been introduced and is becoming a hotspot [7-10]. Some studies have reported the oncology and safety outcomes between NOSE surgery and conventional laparoscopic surgery are comparable [1013]. And the NOSE surgery, therefore, is supposed to have a progress of minimally invasive surgery.

Recently, some meta-analysis studies had compared natural orifice specimen extraction (NOSE) with abdominal incision specimen extraction (AISE) in laparoscopic colorectum resection for the colorectal disease [14, 15]. However, colorectum resection comprises right hemicolectomy, left hemicolectomy, and anterior resection, et al. Procedures among those surgeries were largely different. And the surgical procedures and the excision extension between sigmoid and rectum resection are similar. In addition, several studies compared laparoscopic anterior resection with natural orifice specimen extraction (NOSE-LAR) with abdominal incision specimen extraction (AISE-LAR) for sigmoid or rectum tumors were recently released [16-21]. Hence, we conducted this meta-analysis to evaluate the safety of NOSE-LAR in sigmoid and rectal tumors.

\section{Methods}

\section{Study design and inclusion criteria}

This meta-analysis followed the Preferred Reporting Items for Systematic Reviews and Meta-analysis (PRIS MA) statements [22]. The inclusion and selection criteria were determined before starting a literature search. Only when studies, with full-text, on sigmoid or rectal tumors that compared NOSE-LAR and AISE-LAR and reported at least one of the endpoints of focus were retrieved and analyzed. The most comprehensive research was recruited when overlapping researches was conducted by the same team. No language restriction was applied. Conference abstracts, case reports, reviews, robotic surgery, and single-port laparoscopic surgery were not considered.

Selection criteria conformed to the framework of PICO (Participant, Intervention, Comparison, and Outcome). Patients diagnosed with sigmoid or rectal tumors (benign and malignant tumors) requiring surgery were included. Interventions consisted of NOSE-LAR and AISE-LAR. NOSE-LAR was compared with AISE-LAR in all eligible studies. Primary endpoint outcomes were postoperative complications (overall postoperative complication, abdominal incision-related complication, anastomotic leak, and severe complication (Clavien-Dindo classification $\geq$ III)) and pathologic results (retrieved lymph nodes, proximal resection edge, distal resection edge). Secondary outcomes included operation time, blood loss, pain score (numeric rating scale score), additional analgesics, gastrointestinal function recovery, hospitalization duration, 5-year disease-free survival (DFS), and 5-year overall survival (OS) [23].

\section{Search strategy}

The following databases had been searched up to August 2019: MEDLINE (PubMed), CENTRAL (Cochrane Central Register of Controlled Trials), Embase, Scopus, and ClinicalTrials. For a more accurate search, the following keywords and/or MeSH terms were used: "Sigmoid Neoplasms," "Rectal Neoplasms," "Colorectal Neoplasms," "Laparoscopy," "natural orifice specimen extraction," "transvaginal specimen extraction," "transanal specimen extraction," and "transrectal specimen extraction." The specific search strategies among databases existed differences. The search strategy of PubMed was presented in Additional Text 1. Reference articles of the eligible studies were reviewed to find the potentially relevant studies.

\section{Study selection and quality assessment}

Retrieved studies were independently assessed for relevance by 2 reviewers (Chang-Jian Wang and Jin-Ming Chen) by screening the title and abstract. In order to enhance sensitivity, studies were removed only when both reviewers excluded the study. Subsequently, a full-text assessment was performed on the initial screening included studies. The risk of bias was assessed by the Newcastle-Ottawa Scale (NOS, for observational studies), and studies achieving five or more stars were eligible. Cochrane Collaboration's tool for assessing risk for bias was used for randomized controlled trials [24, 25]. All discrepancies were discussed before a final decision was made.

\section{Data collection and statistical analysis}

Data from the recruited studies were extracted by two reviewers (Chang-Jian Wang and Jin-Ming Chen) and used for further analysis. Outcome values (mean 
(standard deviation) and median (interquartile range)) were extracted from each study. Considering potential heterogeneity among studies, we pooled the results by using a random-effects model. The weighted mean difference (WMD) and 95\% confidence intervals (CIs) were applied for continuous variables, and the odds ratio (OR) and 95\% CIs were used for dichotomous variables. The continuous outcomes were adopted the inverse variance method, and dichotomous outcomes were adopted the Mantel-Haenszel statistical method. When a study merely offered the outcomes with median and interquartile range, an estimation based on formulas designed by Hozo et al. was performed [26]. If a study did not provide the hazard ratio (HR) and 95\% CIs of 5-year DFS or/and OS, the methods presented by Tierney et al. were used for data extraction from survival curves [27]. The chi-square test and $I$-squared value were used for measuring heterogeneity, and $I^{2}>50 \%(P<0.10)$ was defined as significant heterogeneity. Sensitivity analyses (based on NOS score $\geq 6$ and the sample size of NOSE-LAR group $\geq 30$ ) were conducted to assess the potential source of heterogeneity and the robustness of the results.
Publication bias was examined with a funnel plot and Harbord test. $P<0.05$ was considered statistically significant. The statistical analysis was performed on STATA 12.0 software.

\section{Results}

\section{Literature selection and characteristics}

The initial database search identified 342 articles, of which 309 were removed based on the title and abstract assessment. The rest of the literature were evaluated by full-text assessment, and 23 studies were excluded. Characteristics of the excluded studies were presented in Additional Table 1 . Ten studies were finally included for further qualitative and quantitative synthesis [11, 13, $15-19,21,28,29]$. All of these were retrospective studies. The process of the article search and selection was shown in Fig. 1. A total of 1787 patients were recruited in those studies, with 804 patients in the NOSE-LAR group and 983 patients in the AISE-LAR group. The main characteristics of studies and patients were presented in Table 1, and details were shown in Additional

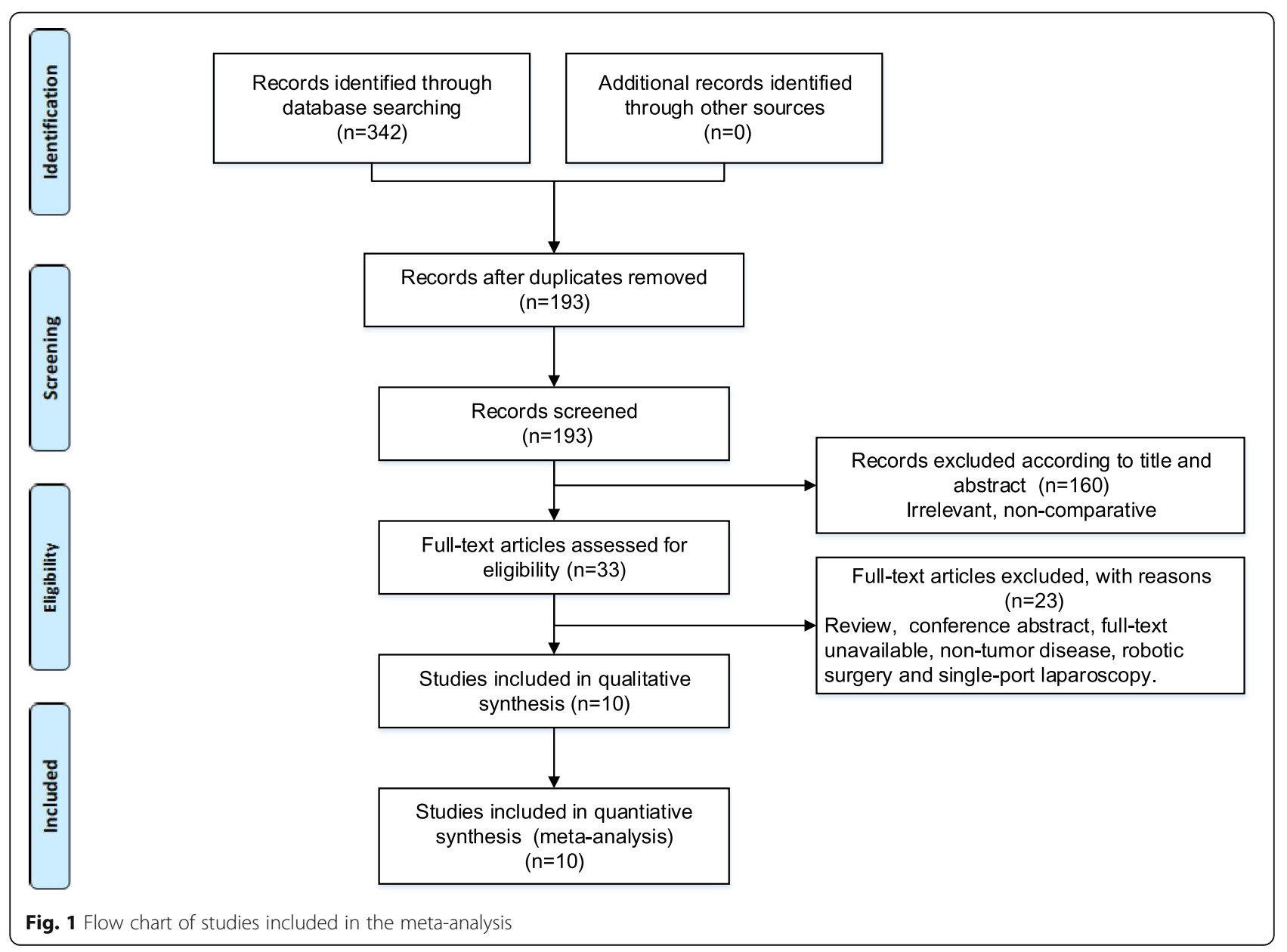




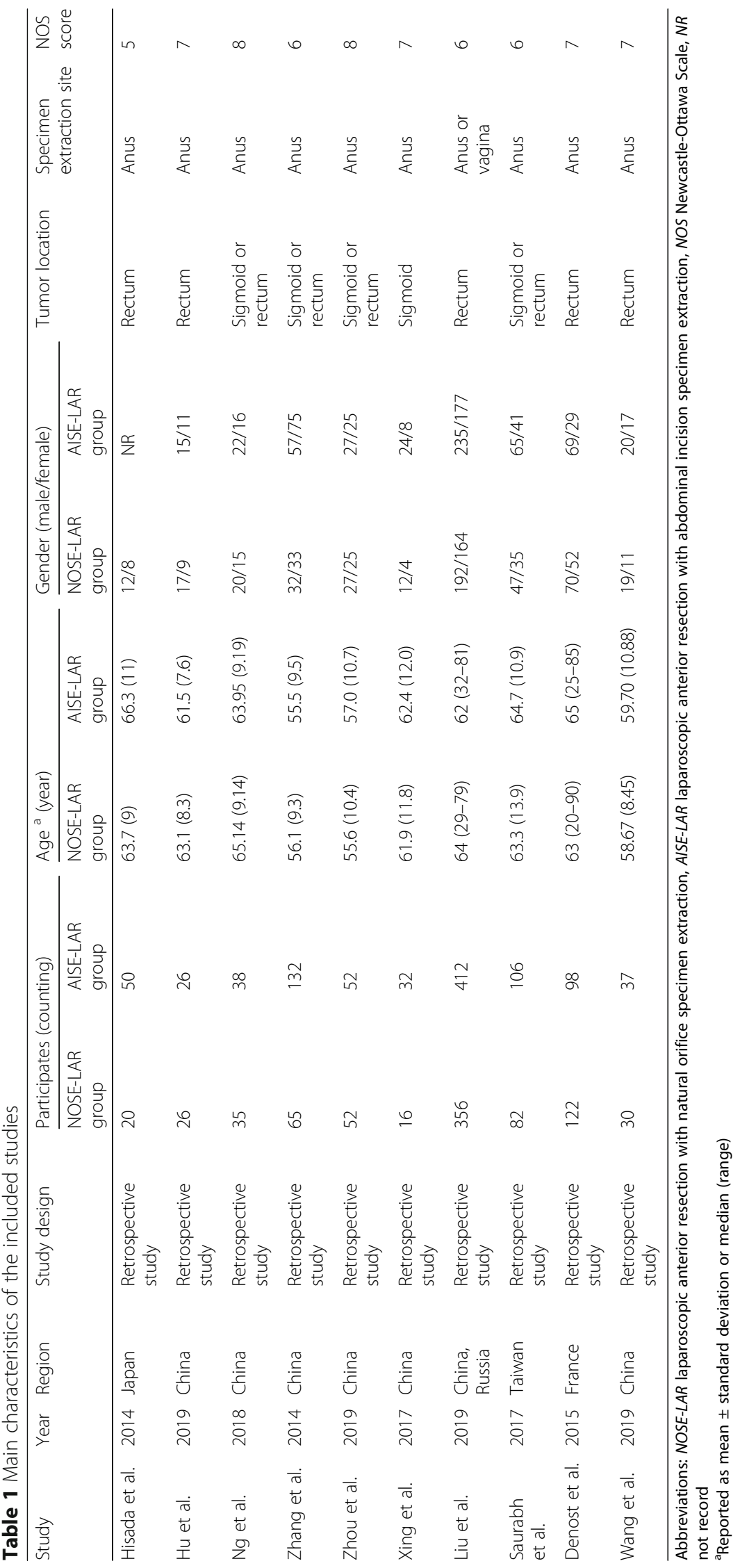




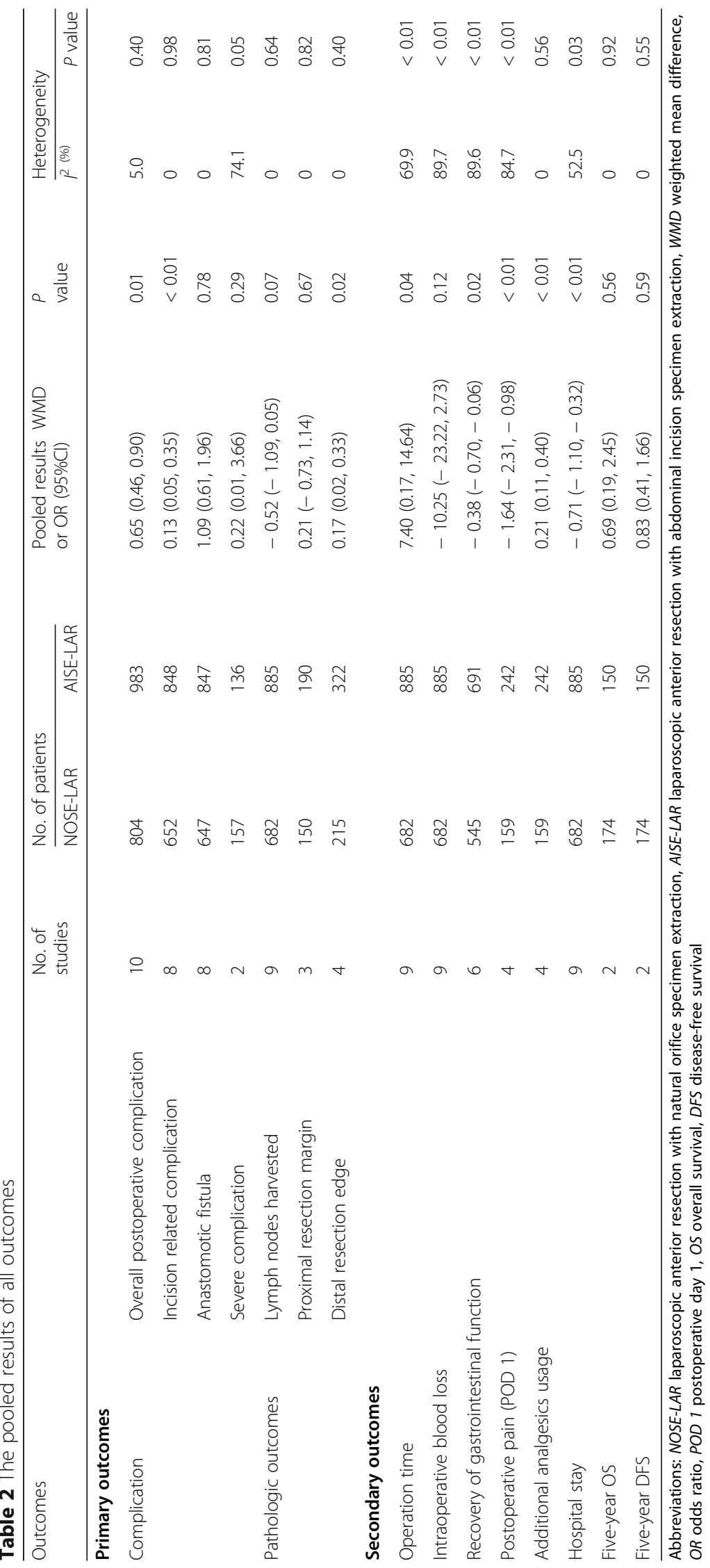


Table 2. The results of the pooled outcomes were summarized in Table 2.

\section{Primary outcomes}

All included studies reported the overall postoperative complication. The pooled data revealed that the postoperative complication in $88(10.9 \%)$ of 804 patients who treated with NOSE-LAR and 146 (14.9\%) of 983 patients who treated with AISE-LAR; the OR was 0.65 (95\% CI, 0.46 to $0.90 ; P=0.01)$ with low heterogeneity $\left(I^{2}=5 \%\right)$ (Fig. 2a). Among the 10 studies, eight studies reported the incision-related complication in $1(0.2 \%)$ of 652 patients who underwent NOSE-LAR and 50 (5.9\%) of 848 patients who underwent AISE-LAR; the OR was 0.13 (95\% CI, 0.05 to $0.35 ; P<0.01)$ with no heterogeneity $\left(I^{2}\right.$ $=0 \%)$ (Fig. 2b). Nine studies reported the anastomotic fistula, of which $\mathrm{Ng}$ et al. reported zero events in both groups. The remaining eight studies recorded anastomotic fistula in $22(3.4 \%)$ of 647 patients suffered NOSE-LAR and 29 (3.4\%) of 847 patients suffered AISELAR; OR was 1.09 (95\% CI, 0.61 to $1.96 ; P=0.78)$ with no heterogeneity $\left(I^{2}=0 \%\right)$ (Fig. 2c). A severe complication was defined based on the Clavien-Dindo classification [30]. Two of the included studies recorded severe complication (Clavien-Dindo classification $\geq \mathrm{III}$ ), and the severe complication in 18 (11.5\%) of 157 patients with NOSE-LAR and 31 (22.8\%) of 136 patients with AISELAR; OR was $0.22(95 \% \mathrm{CI}, 0.01$ to $3.66 ; P=0.29)$ with significant heterogeneity $\left(I^{2}=74 \%\right)$ (Fig. $2 \mathrm{~d}$ ).

A total of nine studies reported lymph node harvest. There was no significant difference in lymph node harvest between the two groups (WMD $=-0.52 ; 95 \% \mathrm{CI},-1.09$ to $0.05 ; P=0.07)$. No significant heterogeneity was observed $\left(I^{2}=0 \%\right)$ (Fig. 3a). The mean number of dissected lymph nodes in the NOSE-LAR group was 15.2 and the AISE-LAR group was 16.3. The proximal resection margin was reported in 3 studies, and the WMD in the upper resection edge was $0.21 \mathrm{~cm}(95 \% \mathrm{CI},-0.73$ to $1.14 \mathrm{~cm} ; P=$ 0.67 ) with no heterogeneity $\left(I^{2}=0 \%\right)$ (Fig. 3b). The distal resection margin was reported in 4 studies, and the WMD in the inferior resection edge was $0.17 \mathrm{~cm}(95 \% \mathrm{CI}, 0.02$ to $0.33 \mathrm{~cm} ; P=0.02)$ with no heterogeneity $\left(I^{2}=0 \%\right.$ ) (Fig. 3c). The length of the distal resection margin in the two groups was $3.81 \mathrm{~cm}$ (NOSE-LAR group) and $3.51 \mathrm{~cm}$ (AISE-LAR group).

\section{Secondary outcomes}

A total of nine studies recorded operation time and intraoperative blood loss. The pooled data revealed that the WMD of operative duration was $7.4 \mathrm{~min}(95 \% \mathrm{CI}$, 0.17 to $14.64 \mathrm{~min} ; P=0.04$; heterogeneity, $I^{2}=69.9 \%$ ) (Fig. 4a). The WMD of blood loss was $-10.25 \mathrm{ml}(95 \%$ CI, -23.22 to $2.73 \mathrm{ml} ; P=0.12$; heterogeneity, $I^{2}=$ 89.7\%) (Fig. 4b).

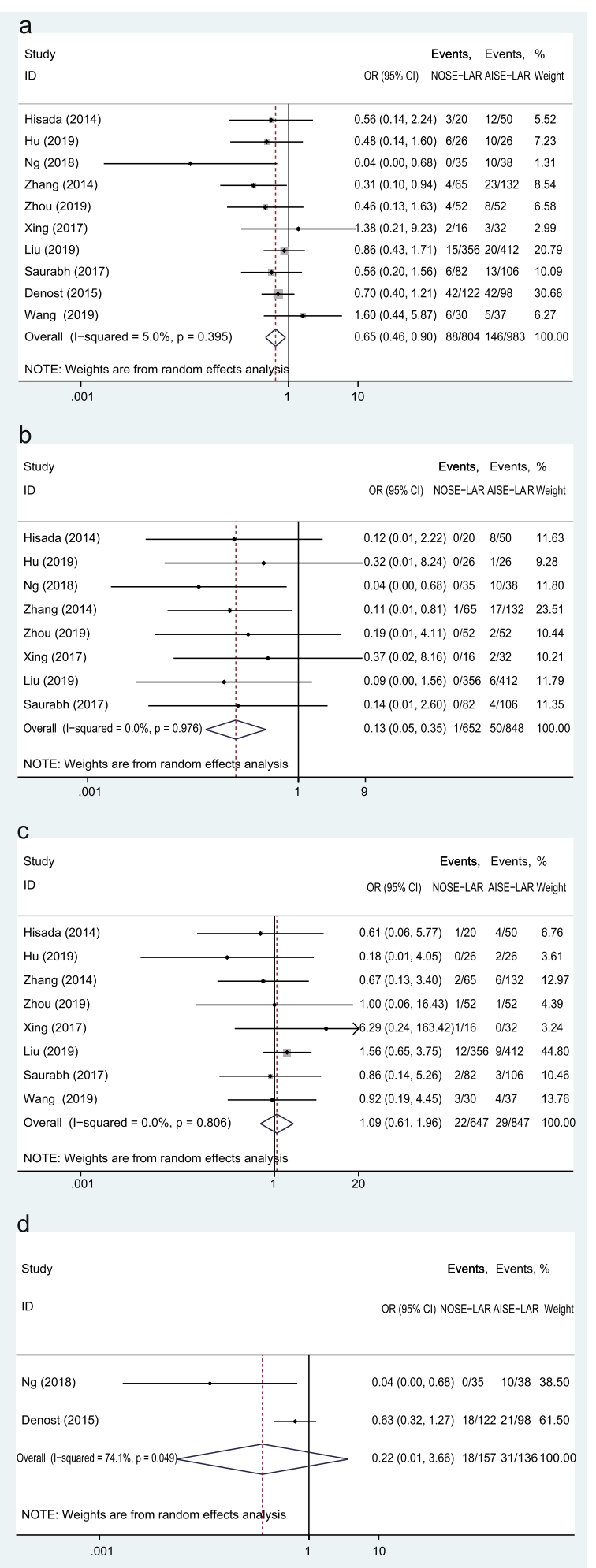

Fig. 2 Forest plot comparing postoperative complications in the NOSE-LAR group and AISE-LAR group: a overall postoperative complication, b incision-related complication, c anastomotic fistula, and $\mathbf{d}$ severe complication 


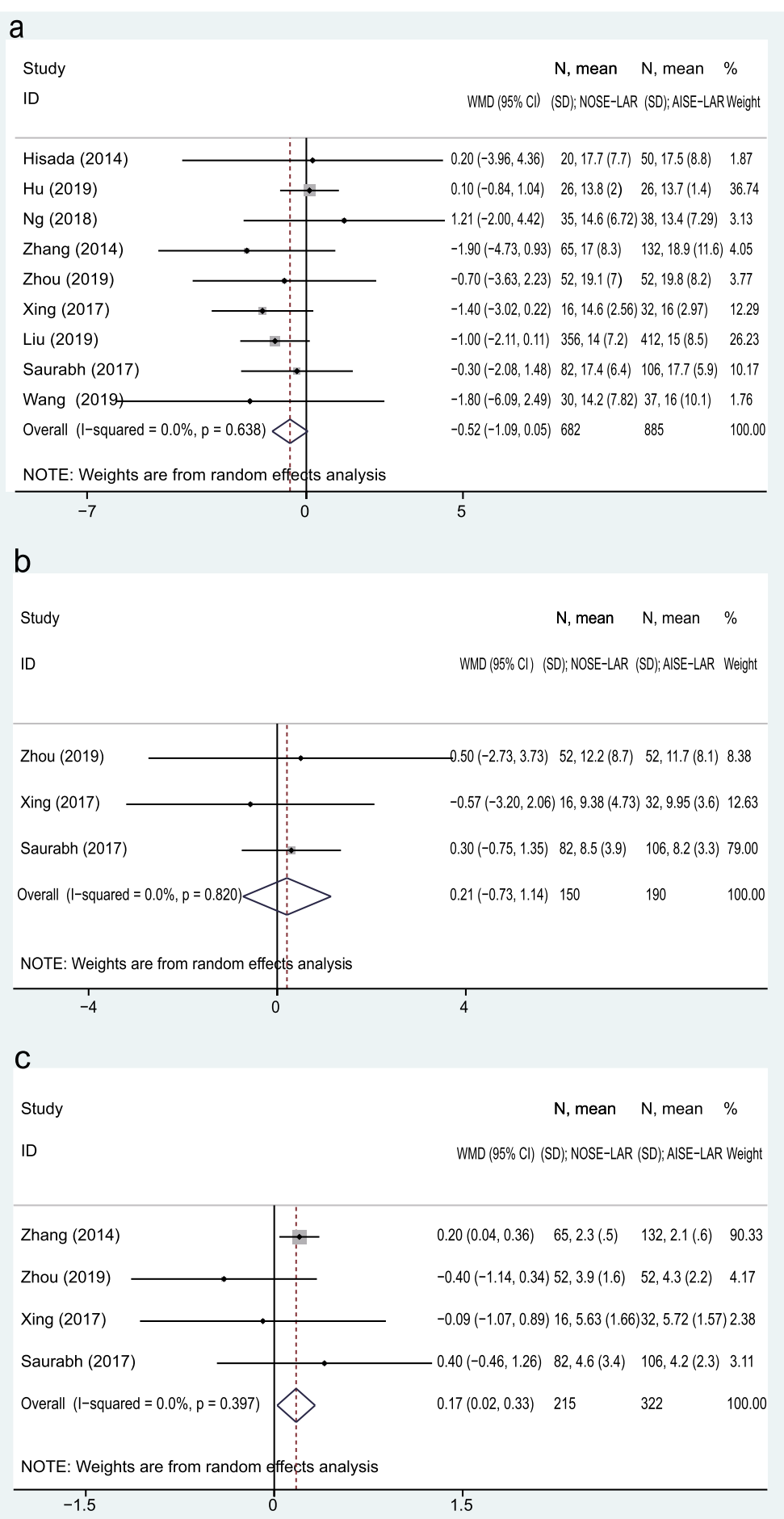

Fig. 3 Forest plot comparing pathologic outcomes in the NOSE-LAR group and AISE-LAR group: a lymph nodes harvested, $\mathbf{b}$ proximal resection margin, and $\mathbf{c}$ distal resection edge

Six studies provided data about the recovery of gastrointestinal function. The WMD of bowel movement was - 0.38 day $(95 \% \mathrm{CI},-0.70$ to -0.06 day; $P=0.02$; heterogeneity, $I^{2}=89.6 \%$ ) (Fig. $5 \mathrm{a}$ ). The postoperative pain was recorded in 6 studies, and 2 studies (Hisada et al. and Wang et al.) recorded the postoperative pain period and the remaining 4 reported the pain scores in postoperative day 1 (POD 1). The WMD of pain score in POD 

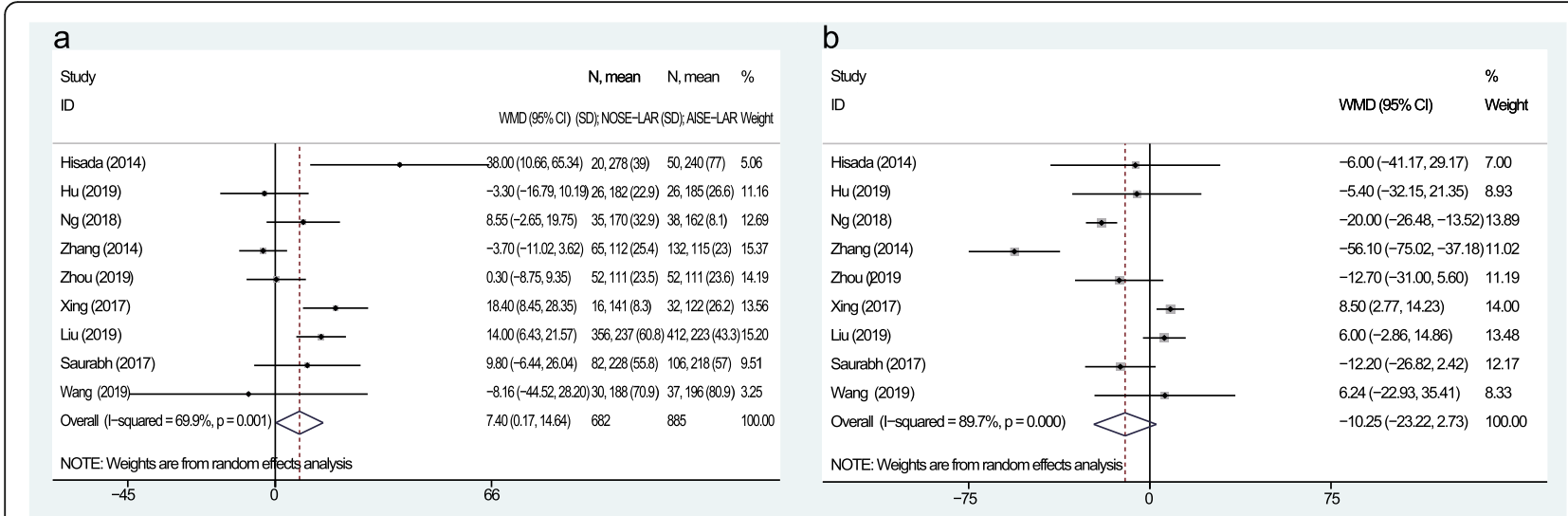

Fig. 4 Forest plot comparing intraoperative outcomes in the NOSE-LAR group and AISE-LAR group: a operation time and b blood losS

1 was - 1.64 (95\% CI, -2.31 to $-0.98 ; P<0.01$; heterogeneity, $I^{2}=84.7 \%$ ) (Fig. $5 \mathrm{~b}$ ). The additional analgesic usage rate was also reported in those 4 studies, and the OR of additional analgesics usage was 0.21 (95\% CI, 0.11 to $0.40 ; P<0.01$; heterogeneity, $I^{2}=0 \%$ ) (Fig. $5 \mathrm{c}$ ). The duration of hospital stay was reported in nine studies, the WMD of hospital stay was - 0.71 day $(95 \% \mathrm{CI}$, 1.10 to -0.32 day; $P<0.01$; heterogeneity, $\left.I^{2}=52.5 \%\right)$ (Fig. 5d).

Five-year disease-free survival (DFS) and 5-year overall survival (OS) were available in two studies. The hazard ratio (HR) in the 5-year DFS was 0.83 (95\% CI, 0.41 to 1.66; $P=0.59$ ); heterogeneity, $I^{2}=0 \%$ ) (Fig. 6a), and the HR in the 5 -year OS was 0.69 (95\% CI, 0.19 to $2.45 ; P=$ 0.56; heterogeneity, $I^{2}=0 \%$ ) (Fig. 6b).

\section{Sensitivity analysis}

Sensitivity analysis results based on the NOS score $\geq 6$ and the sample size of NOSE-LAR group $\geq 30$ were presented in Additional Table 3. It showed a slight inconsistency in distal resection edge, operation time, and recovery of gastrointestinal function. And all the other outcomes showed a similar trend of results between the two groups.

\section{Publication bias}

A funnel plot of overall postoperative complication was performed to detect publication bias. It showed that all the inclusive studies were within the $95 \%$ confidence interval, and no publication bias was found (Fig. 7). In addition, a Harbord test confirmed there was no publication bias $(P=0.59)$.

\section{Discussion}

As a technique used for clinical treatment, the safety of NOSE-LAR should be efficiently proved. Morbidity is one of the most efficient indicators for assessing the safety of an emerging technique. Postoperative complications may not only lead to failures of surgery but also threaten lives. The overall postoperative complication rate in NOSE-LAR (10.9\%) was lower than that in AISELAR (14.9\%). Severe morbidity (Clavien-Dindo $\geq$ III) among the two techniques was not a significant difference. The operation involving digestive tract reconstruction, anastomotic leakage is a potential risk. Once it occurs, reoperation is usually inevitable [31]. The incidence of anastomotic leakage in NOSE-LAR (3.4\%) was similar with that in AISE-LAR (3.4\%). In addition, the incidence of incision-related complications in NOSELAR (0.2\%) was significantly lower than that in the AISE-LAR group (5.9\%). Obviously, the reduction of complications in NOSE-LAR has largely attributed to the decrease of incision-related complications. Although the complications in NOSE-LAR were reduced, the risk of bacteria contamination in the peritoneal cavity should not be neglected. Costantino et al. had reported the peritoneal contamination in the NOSE group was higher than that of the conventional group [32]. Hence, measures such as bowel preparation, prophylactic antibiotics, peritoneal irrigation, transanal lavage, transluminal wound retractor, and abdominal drains are recommended to avoid the contamination of the peritoneal cavity [33].

The postoperative pathology results, to some extent, also reflect the safety of a surgery [3]. This meta-analysis showed lymph nodes harvested between the two groups was comparable, and it also conformed to the minimum requirement of the guideline (retrieved more than 12 nodes) [15]. In our meta-analysis, the proximal margin in the NOSE-LAR group was similar with the conventional group. However, the distal margin in the NOSE group was longer than that of the AISE-LAR group. The 


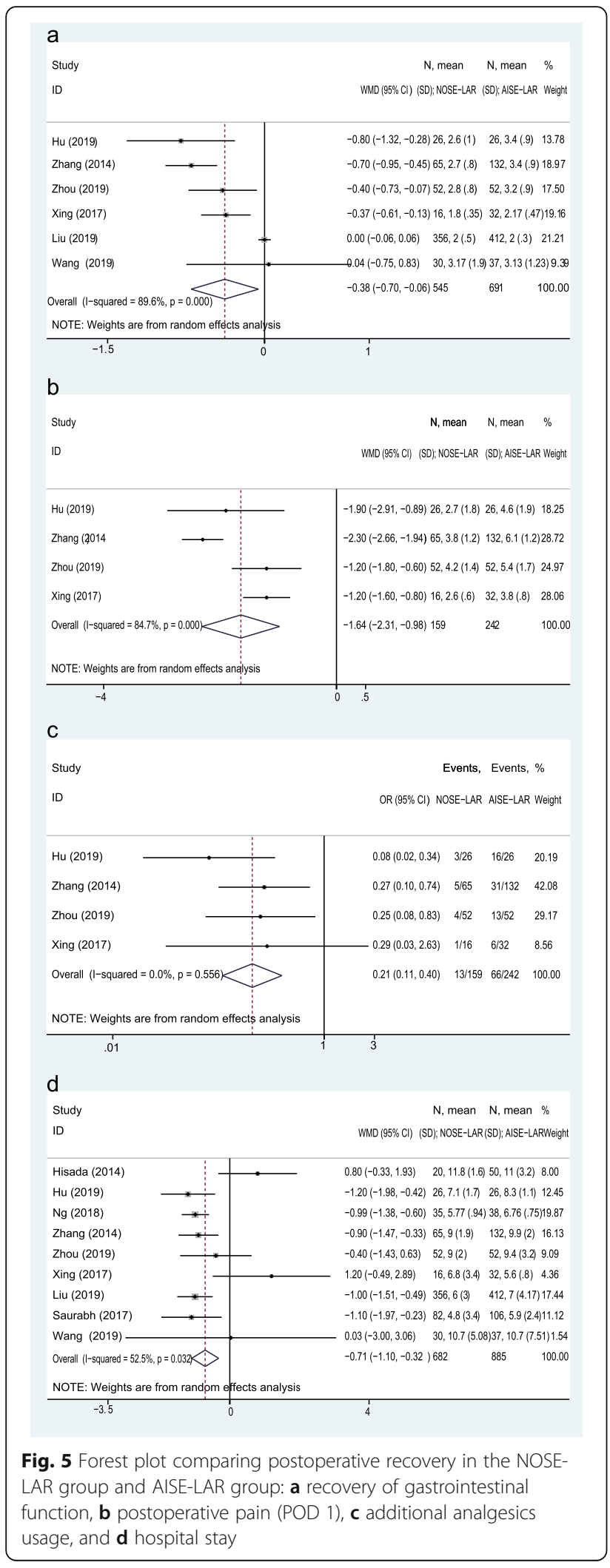

potential cause of this difference was the use of transanal specimen eversion and extra-abdominal resection technique in the NOSE group [11, 13, 21]. Because of this procedure, the distal rectal resection is performed extraabdominally under direct vision. Moreover, circumferential resection margin (CRM) between the two groups have no difference $[11,20,21,28]$. In addition, according to our meta-analysis, the long-term outcomes (5-year DFS and 5-year OS) were comparable. All of those indicated the NOSE technique was a safety procedure in the treatment of sigmoid and rectal cancers. Nevertheless, a concern about tumor seeding was raised during the procedure of enterotomy and specimen extraction. It is necessary to apply several measures such as the use of protection devices (sterile specimen bags) and avoiding over-pulling and compression during specimen extraction [33].

As a minimally invasive surgery, NOSE-LAR had more advantages in alleviating patient's distress. The reduction of pain scores in postoperative day 1 (POD 1) was observed and this reduction could be attributed to the trauma in NOSE-LAR being further reduced [34]. Owing to less pain, the need for additional analgesics was also reduced. In addition, accelerating postoperative recovery was also observed. The recovery of gastrointestinal function and hospital duration in patients who suffered NOSE-LAR was much shorter. Besides, some scholars may doubt if there have alterations in sexual, urinary, or defecation function in the groups. According to the included studies, there were no differences in functional outcomes such as sexual, urinary, or defecation between two groups [13, 21]. Even though a small part of patients experienced function alteration, and the alternation was reversible [11, 16, 28]. Those all demonstrated that NOSE-LAR was a safety surgery, and to some extent, it had advantages in postoperative recovery.

Nevertheless, our study has several limitations. Firstly, intersphincteric resections were mixed with coloanal anastomoses with sigmoid cancer in our studies. Although there exist some differences, we mixed the two techniques and mainly considered there existing common procedures between sigmoid and rectum resection in laparoscopic anterior resection. And some studies did not record the methods of outcome evaluation (such as blood loss evaluation). To some extent, it reduces the comparability of outcomes. Secondly, the present metaanalysis relied solely on retrospective studies and some original studies not presented how patients were selected to be candidates for one technique or another; the quality of all included studies was regarded as fair or good [35]. However, this type of study cannot be compared with a randomized controlled trial, and potential bias cannot be ruled out. Thirdly, this study only recruited one multicenter research and some outcomes included 


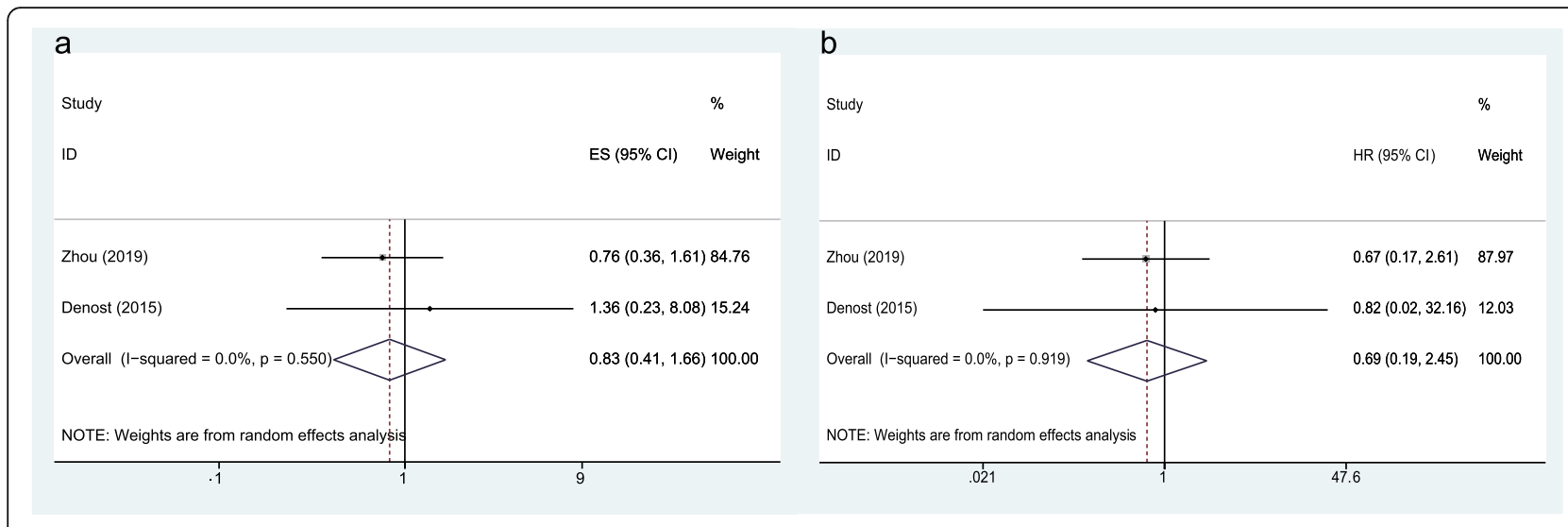

Fig. 6 Forest plot comparing long-term outcomes in the NOSE-LAR group and AISE-LAR group: a 5-year DFS and b 5-year OS

limited studies. So further multicenter randomized controlled and more comprehensive studies containing adequate outcomes are needed. Fourthly, the results of some pooled results among studies existed heterogeneity. The sensitivity analysis could not be detected as the cause of heterogeneity. Although some results existed heterogeneity, the major results were homogeneity. And the heterogeneity of outcomes such as operation duration, blood loss, and hospital stay can be explained by clinical heterogeneity such as the difference of patients, surgeons, patient management, and differences in surgical proficiency in NOSE technology. In addition, the results of the major parameters were robust. All in all, the results of this analysis are convinced.

According to our meta-analysis, the advantages of NOSE are reduced overall complications (especially incision-related complications), increased distal resection edge, enhanced recovery of gastrointestinal function, reduced postoperative pain, reduced additional analgesics usage, and shortened hospital stay. And without an auxiliary, patients operated by the NOSE technique achieve better aesthetics. However, the operative time is prolonged. Although the NOSE technique has many advantages, there are many requirements that should be followed before the application of this technique in colorectal surgery. Firstly, the NOSE should be operated by experienced surgeons with conventional laparoscopic colorectal surgery. Secondly, the indication of NOSE should follow the indication of conventional laparoscopic colorectal resection. The depth of tumor invasion should be within T3, and body mass index (BMI) should be less than $30 \mathrm{~kg} / \mathrm{m}^{2}$ for transanal-NOSE and less than $35 \mathrm{~kg} / \mathrm{m}^{2}$ for transvaginalNOSE. Trans-anal NOSE suits for male or female patients, and the tumor diameter is

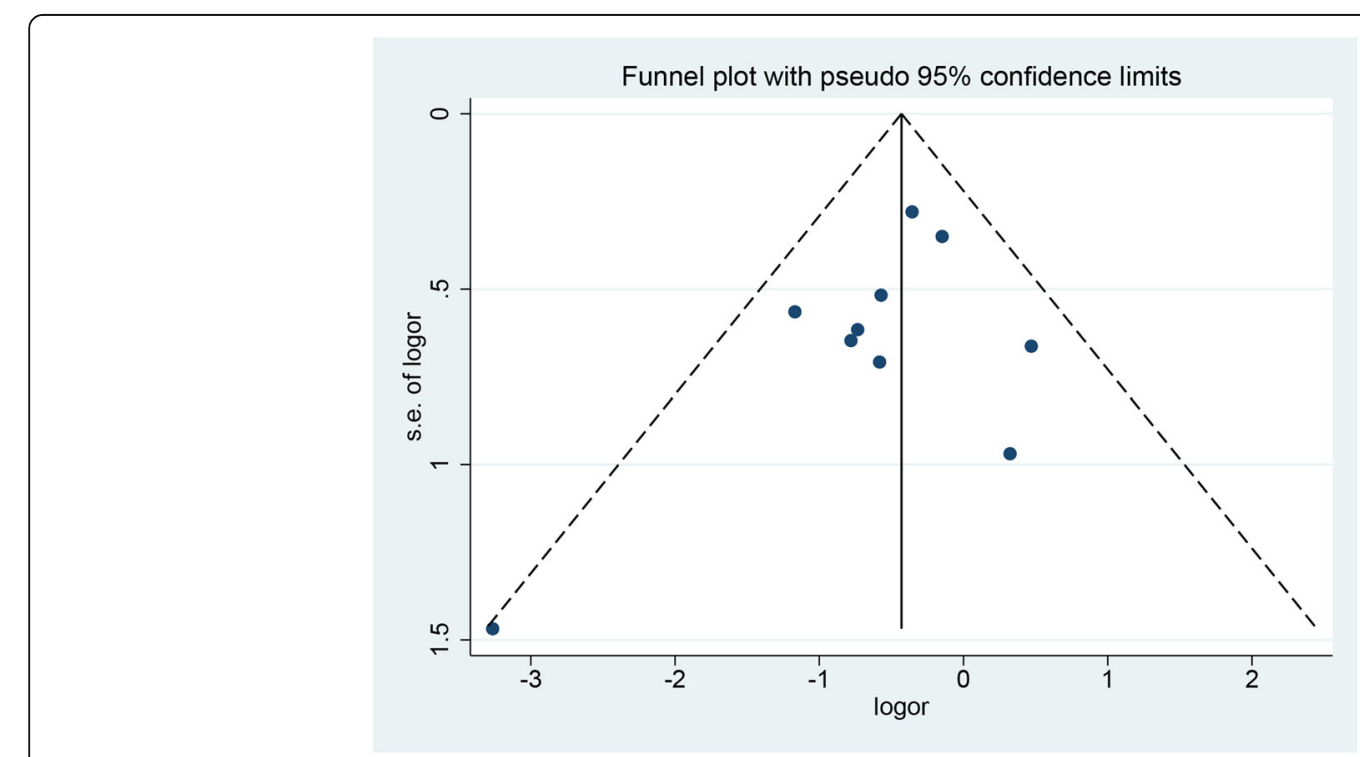

Fig. 7 Funnel plot of the overall postoperative complications 
recommended less than $3 \mathrm{~cm}$. While transvaginal NOSE is only applied for female patients, and the tumor diameter is limited within $5 \mathrm{~cm}$. And the emergent conditions such as bowel obstruction, perforation, and massive bleeding are excluded [33].

\section{Conclusion}

All in all, as surgeons follow appropriate indications, the NOSE-LAR for sigmoid or rectal tumors is a safe surgery. And the long-term outcomes between two operations have no difference, and the benefits of the NOSE-LAR in short-term outcomes are noticeable. These findings promote enthusiasm in support of NOSE surgery as an alternative approach for the treatment of sigmoid and rectal tumors.

\section{Supplementary information}

Supplementary information accompanies this paper at https://doi.org/10. 1186/s12957-020-01982-w.

Additional file 1. Additional file Text 1. The search strategy of Pubmed. Additional file 2:. Additional Table 1. Characteristics of the excluded studies.

Additional file 3. Additional Table 2. Summary of the included studies Additional file 4. Additional Table 3 . The results of sensitivity analysis. Additional file 5. Additional Table 4. Quality assessment based on the NOS for retrospective studies.

\section{Abbreviations}

NOSE-LAR: Laparoscopic anterior resection with natural orifice specimen extraction; AISE-LAR: Laparoscopic anterior resection with abdominal incision specimen extraction; WMD: Weighted mean difference; OR: Odds ratio; NOS: Newcastle-Ottawa Scale; DFS: Disease-free survival; OS: Overall survival; Cls: Confidence intervals; HR: Hazard ratio; POD 1: Postoperative day 1

\section{Acknowledgements}

We wish to thank the timely help given by Jun-Feng $\mathrm{Hu}$ in statistic analysis and Meng-Dan Zhou in language editing.

\section{Authors' contributions}

Guan-Gen Yang and Zhong Shen contributed to the conception and design of the study. Jun He performed the literature search and the writing of the manuscript. Chang-Jian Wang and Jin-Ming Chen performed the data extraction. Hai-Bo Yao performed the data analysis. Qin-Yan Yang and Jian-Ming Qiu participated in the writing of the manuscript. Guan-Gen Yang and HaiBo Yao helped to revise the intellectual content. The authors read and approved the final version of the manuscript.

\section{Funding}

This work was funded by the Zhejiang Natural Science Foundation (Grant No. LQ19H160013) and the Zhejiang Medical Health Science and Technology Project (Grant No. 2019323421) and the Hangzhou Health Science and Technology Project (Grant no. 2017A26).

\section{Availability of data and materials}

All the data analyzed in this study was obtained from the included original articles or related authors.

\section{Ethics approval and consent to participate}

Not applicable.

\section{Consent for publication}

Not applicable.

\section{Competing interests}

The authors declare that they have no competing interests.

\section{Author details}

${ }^{1}$ Department of Colorectal Surgery, Hangzhou Third Hospital, Hangzhou 310009 Zhejiang, People's Republic of China. ${ }^{2}$ Departments of

Gastroenterology \& Pancreatic Surgery, Zhejiang Provincial People's Hospital, Hangzhou 310014 Zhejiang, People's Republic of China.

Received: 28 February 2020 Accepted: 31 July 2020

Published online: 19 August 2020

\section{References}

1. Wang $\mathrm{CL}, \mathrm{Qu} \mathrm{G}, \mathrm{Xu}$ HW. The short- and long-term outcomes of laparoscopic versus open surgery for colorectal cancer: a meta-analysis. Int J Color Dis. 2014;29(3):309-20.

2. Ishibe A, Ota M, Fujii S, Suwa Y, Suzuki S, Suwa H, Momiyama M, Watanabe J, Watanabe K, Taguri M, et al. Midterm follow-up of a randomized trial of open surgery versus laparoscopic surgery in elderly patients with colorectal cancer. Surg Endosc. 2017;31(10):3890-7.

3. Allaix ME, Giraudo G, Mistrangelo M, Arezzo A, Morino M. Laparoscopic versus open resection for colon cancer: 10-year outcomes of a prospective clinical trial. Surg Endosc. 2015;29(4):916-24.

4. Lee L, Abou-Khalil M, Liberman S, Boutros M, Fried GM, Feldman LS Incidence of incisional hernia in the specimen extraction site for laparoscopic colorectal surgery: systematic review and meta-analysis Surg Endosc. 2017;31(12):5083-93.

5. Hennessey DB, Burke JP, Ni-Dhonochu T, Shields C, Winter DC, Mealy K. Risk factors for surgical site infection following colorectal resection: a multiinstitutional study. Int J Color Dis. 2016;31(2):267-71.

6. Goto S, Hasegawa S, Hata H, Yamaguchi T, Hida K, Nishitai R, Yamanokuchi S, Nomura A, Yamanaka T, Sakai Y. Differences in surgical site infection between laparoscopic colon and rectal surgeries: sub-analysis of a multicenter randomized controlled trial (Japan-Multinational Trial Organization PREV 07-01). Int J Color Dis. 2016;31(11):1775-84.

7. Park JS, Choi GS, Lim KH, Jang YS, Kim HJ, Park SY, Jun SH. Clinical outcome of laparoscopic right hemicolectomy with transvaginal resection, anastomosis, and retrieval of specimen. Dis Colon Rectum. 2010;53(11): 1473-9.

8. Ooi BS, Quah HM, Fu CW, Eu KW. Laparoscopic high anterior resection with natural orifice specimen extraction (NOSE) for early rectal cancer. Tech Coloproctol. 2009;13(1):61-4.

9. Franklin MJ, Kelley H, Kelley M, Brestan L, Portillo G, Torres J. Transvaginal extraction of the specimen after total laparoscopic right hemicolectomy with intracorporeal anastomosis. Surg Laparosc Endosc Percutan Tech. 2008; 18(3):294-8.

10. Wolthuis AM, de Buck VOA, D'Hoore A. Laparoscopic natural orifice specimen extraction-colectomy: a systematic review. World J Gastroenterol. 2014;20(36):12981-92.

11. Xingmao $Z$, Haitao $Z$, Jianwei $L$, Huirong $H$, Junjie $H$, Zhixiang $Z$. Totally laparoscopic resection with natural orifice specimen extraction (NOSE) has more advantages comparing with laparoscopic-assisted resection for selected patients with sigmoid colon or rectal cancer. Int J Color Dis. 2014; 29(9):1119-24.

12. Leung AL, Cheung HY, Fok BK, Chung CC, Li MK, Tang CN. Prospective randomized trial of hybrid NOTES colectomy versus conventional laparoscopic colectomy for left-sided colonic tumors. World J Surg. 2013; 37(11):2678-82.

13. Hisada M, Katsumata K, Ishizaki T, Enomoto M, Matsudo T, Kasuya K, Tsuchida A. Complete laparoscopic resection of the rectum using natural orifice specimen extraction. World J Gastroenterol. 2014;20(44):16707-13.

14. Ma B, Huang XZ, Gao P, Zhao JH, Song YX, Sun JX, Chen XW, Wang ZN. Laparoscopic resection with natural orifice specimen extraction versus conventional laparoscopy for colorectal disease: a meta-analysis. Int J Color Dis. 2015;30(11):1479-88.

15. Liu RJ, Zhang CD, Fan YC, Pei JP, Zhang C, Dai DQ. Safety and oncological outcomes of laparoscopic NOSE surgery compared with conventional laparoscopic surgery for colorectal diseases: a meta-analysis. Front Oncol. 2019;9:597.

16. Zhou S, Wang X, Zhao C, Pei W, Zhou H, Liu Q, Liang J, Zhou Z, Wang X. Comparison of short-term and survival outcomes for transanal natural 
orifice specimen extraction with conventional mini-laparotomy after laparoscopic anterior resection for colorectal cancer. Cancer Manag Res. 2019;11:5939-48

17. Xing J, Zhang C, Yang X, Wang H, Wang H, Yu E, Fu C. Comparison of shortterm outcomes of transrectal specimen extraction during laparoscopic sigmoid radical resection versus conventional laparoscopically assisted procedure. Zhonghua Wei Chang Wai Ke Za Zhi. 2017;20(6):665-70.

18. Wang R, Wei Z, Liu Q, Li W, Xiao L, Han HF, Yang S. Transanal versus transabdominal specimen extraction in laparoscopic rectal cancer surgery: a retrospective analysis from China. Wideochir Inne Tech Maloinwazyjne. 2019:14(2):203-9.

19. Ng HI, Sun WQ, Zhao XM, Jin L, Shen XX, Zhang ZT, Wang J. Outcomes of trans-anal natural orifice specimen extraction combined with laparoscopic anterior resection for sigmoid and rectal carcinoma: an observational study. Medicine (Baltimore). 2018:97(38):e12347.

20. Liu Z, Efetov S, Guan X, Zhou H, Tulina I, Wang G, Tsarkov P, Wang X. A multicenter study evaluating natural orifice specimen extraction surgery for rectal cancer. J Surg Res. 2019;243:236-41.

21. Hu JH, Li XW, Wang CY, Zhang JJ, Ge Z, Li BH, Lin XH. Short-term efficacy of natural orifice specimen extraction surgery for low rectal cancer. World J Clin Cases. 2019;7(2):122-9.

22. Moher D, Liberati A, Tetzlaff J, Altman DG. Preferred reporting items for systematic reviews and meta-analyses: the PRISMA statement. Ann Intern Med. 2009;151(4):264-9 W64.

23. Hawker GA, Mian S, Kendzerska T, French M. Measures of adult pain: Visual Analog Scale for Pain (VAS Pain), Numeric Rating Scale for Pain (NRS Pain), McGill Pain Questionnaire (MPQ), Short-Form McGill Pain Questionnaire (SFMPQ), Chronic Pain Grade Scale (CPGS), Short Form-36 Bodily Pain Scale (SF-36 BPS), and Measure of Intermittent and Constant Osteoarthritis Pain (ICOAP). Arthritis Care Res. 2011;63(Suppl 11):S240-52.

24. Higgins JP, Altman DG, Gotzsche PC, Juni P, Moher D, Oxman AD, Savovic J, Schulz KF, Weeks L, Sterne JA. The Cochrane Collaboration's tool for assessing risk of bias in randomised trials. BMJ. 2011;343:d5928.

25. GA Wells BSDO: The Newcastle-Ottawa Scale (NOS) for assessing the quality of nonrandomised studies in meta-analyses. 2005.

26. Hozo SP, Djulbegovic B, Hozo I. Estimating the mean and variance from the median, range, and the size of a sample. BMC Med Res Methodol. 2005;5:13.

27. Tierney JF, Stewart LA, Ghersi D, Burdett S, Sydes MR. Practical methods for incorporating summary time-to-event data into meta-analysis. TRIALS. 2007:8:16.

28. Denost Q, Adam JP, Pontallier A, Celerier B, Laurent C, Rullier E. Laparoscopic total mesorectal excision with coloanal anastomosis for rectal cancer. Ann Surg. 2015;261(1):138-43.

29. Saurabh B, Chang SC, Ke TW, Huang YC, Kato T, Wang HM, Tzu-Liang CW, Fingerhut A. Natural orifice specimen extraction with single stapling colorectal anastomosis for laparoscopic anterior resection: feasibility, outcomes, and technical considerations. Dis Colon Rectum. 2017:60(1):43-50.

30. Dindo D, Demartines N, Clavien P-A. Classification of surgical complications: a new proposal with evaluation in a cohort of 6336 patients and results of a survey. Ann Surg. 2004;240(2):205-13.

31. Al-Mazrou AM, Suradkar K, Mauro CM, Kiran RP. Characterization of readmission by day of rehospitalization after colorectal surgery. Dis Colon Rectum. 2017;60(2):202-12.

32. Costantino FA, Diana M, Wall J, Leroy J, Mutter D, Marescaux J. Prospective evaluation of peritoneal fluid contamination following transabdominal vs. transanal specimen extraction in laparoscopic left-sided colorectal resections. Surg Endosc. 2012;26(6):1495-500.

33. Guan X, Liu Z, Longo A, Cai JC, TZu-Liang CW, Chen LC, Chun HK, Manuel DCPJ, Efetov $S$, Escalante $R$, et al. International consensus on natural orifice specimen extraction surgery (NOSES) for colorectal cancer. Gastroenterol Rep (Oxf). 2019;7(1):24-31.

34. Akiyoshi T, Kuroyanagi H, Oya M, Konishi T, Fukuda M, Fujimoto Y, Ueno M, Yamaguchi T. Short-term outcomes of laparoscopic rectal surgery for primary rectal cancer in elderly patients: is it safe and beneficial? Gastrointestinal Surg. 2009;13(9):1614-8.

35. Yang E, Nie D, Li Z. Comparison of major clinical outcomes between transvaginal notes and traditional laparoscopic surgery: a systematic review and meta-analysis. J Surg Res. 2019;244:278-90.

\section{Publisher's Note}

Springer Nature remains neutral with regard to jurisdictional claims in published maps and institutional affiliations.

Ready to submit your research? Choose BMC and benefit from:

- fast, convenient online submission

- thorough peer review by experienced researchers in your field

- rapid publication on acceptance

- support for research data, including large and complex data types

- gold Open Access which fosters wider collaboration and increased citations

- maximum visibility for your research: over $100 \mathrm{M}$ website views per year

At BMC, research is always in progress.

Learn more biomedcentral.com/submissions 